\title{
Bilateral Bipedicled Advancement Nasoseptal Flaps for Nasal Septal Perforation Repair: Endoscopic Versus Open Rhinoplasty Approach
}

Original Article

\author{
Ashraf A. Eldemerdash, Ahmad M. Hamdan, Ibrahim A. Abdel-Shafy \\ Department of Otorhinolaryngology, Faculty of Medicine, Menoufia University, Shebin \\ El-Kom, Egypt.
}

\begin{abstract}
Objective: To compare open rhinoplasty and endoscopic approaches with bilateral bipedicled advancement nasoseptal flaps in nasal septal perforation repair.

Patients and Methods: The current study is a prospective comparative study including 53 patients with symptomatic cartilaginous septal perforation recruited from Otorhinolaryngology department, Menoufia University and distributed as 2 groups. Group I included 25 patients subjected to open approach. Group II included 18 patients subjected to endoscopic approach. Both groups were compared regarding success defined as complete or partial closure, operative details including operative duration and intraoperative blood loss, and postoperative details including patient discomfort, nasal crustations and aesthetic problems. The relationship between the success of each technique and the vertical and anteroposterior diameters of the perforation was assessed.

Results: The success rate of open and endoscopic approaches were $80 \%$ and $72.2 \%$ respectively with no statistically significant difference $(p=0.55)$. There was a statistically significant relationship between the success of both approaches and the vertical diameter of the perforation $(p=0.001$ and 0.002 , respectively) There was no statistically significant difference between both groups regarding operative duration and bleeding. ( $p=0.73$ and 0.52 , respectively). There was a statistically significant difference regarding discomfort and aesthetic problems favoring the endoscopic approach $(p=0.004$ and 0.04 , respectively).

Conclusion: Both approaches are successful options for repair of nasal septal perforation with comparable results and operative details. However, the open approach may cause more discomfort and aesthetic problems. The vertical diameter of the perforation is a significant determinant of the success of both approaches.
\end{abstract}

Key Words: Bipedicled flaps, endoscopic, mucosal flaps, nasal septal perforation, open rhinoplasty

Received: 23 June 2020, Accepted: 31 August 2020

Corresponding Author: Ahmad Mahmoud Hamdan, Department of Otorhinolaryngology, Faculty of Medicine, Menoufia University, Shebin El-Kom, Menoufia, Egypt, Tel.: 00201008993175, E-mail: Ahmed.Hamdan@med.menofia.edu.eg

ISSN: 2090-0740, November 2020 Vol. 21, No.3

\section{INTRODUCTION}

Nasal septal perforations, although uncommon, are the focus of several studies to assess their management. They lead to impairment of air flow and pressure which leads to a wide variety of symptoms including crusting, epistaxis, whistling and cacosmia. Anterior and wide septal perforations are more symptomatic, while posterior perforations tend to be less symptomatic, due to humidification from the turbinates ${ }^{[1]}$. Septal perforations are difficult problems to manage. Identification of the cause, which is mostly iatrogenic, is essential before selecting the approach for management. Patients with perforations caused by granulomatous diseases or tumors of the nose are not fit for surgical intervention. The treatment of symptomatic perforations should start with a trial of medical treatment including nasal lavage and emollients to alleviate the associated crustations and epistaxis. Surgical treatment is indicated after failure of such medical treatment with persistence of symptoms ${ }^{[2]}$. Limiting factors that make the surgical repair difficult include presence of insufficient mucosa, structural abnormalities, and inappropriate systemic conditions of the patients. There is no standard surgical approach in NSP closure. Selection of the surgical approach depends on the perforation characteristics and surgeon experience ${ }^{[3]}$.

All surgical procedures for repair of nasal septal perforations are based on using mucosal, mucoperichondrial and/or mucoperiosteal flaps with or without interposition of a graft material between mucosal flaps ${ }^{[4]}$. Various surgical approaches have been described for the surgical repair of NSP including open rhinoplasty, endonasal, sublabial and midfacial degloving approaches depending on the size of NSP. Different types of flaps have been designed 
to reconstruct the nasal septum. Most commonly used flaps are advancement septal mucosal flaps (unilateral or bilateral), inferior turbinate, upper lateral cartilage, inner mucoperichondrial flap, middle turbinate flap, facial artery musculomucosal pedicled flap, oral mucosal flap and radial forearm free flap ${ }^{[5]}$.

\section{AIM OF THE STUDY}

The aim of this study was to compare open rhinoplasty and endoscopic approaches with bilateral bipedicled advancement nasoseptal flaps for nasal septal perforation repair.

\section{PATIENTS AND METHODS}

The current study was a prospective comparative study conducted during the period from July 2015 to January 2020 after approval of the ethical committee of the faculty. The patients of this study were recruited from Otorhinolaryngology Department, Menoufia University. A written consent was taken from every patient before participation in the study.

To be included in the study, every patient should have nasal septal perforation involving the cartilaginous septum. The cause of the perforation should be either idiopathic traumatic or postoperative. The nasal septal perforation should be symptomatizing indicating surgical intervention for repair.

Any patient with history of systemic diseases interfering with healing including diabetes mellitus, liver diseases and autoimmune diseases was excluded from the study. Self-inflicted nasal septal perforation, local conditions of the nose interfering with repair of the perforation including granulomata (syphilis, scleroma, TB, sarcoidosis or Wagner's granulomatosis), and nasal and paranasal neoplasia were criteria for exclusion from the study.

Surgical unfitness including bleeding tendencies and uncontrolled cardiac diseases was a cause for exclusion from the study. Every patient included in the study was subjected to the following protocol:

Preoperative Assessment: All study patients were assessed by history taking to define the cause of the perforation and the presence or absence of symptoms of perforation (crusting, epistaxis, pain, discharge, obstruction, whistling). Anterior rhinoscopy was performed to define the presence of nasal septal perforation, its site whether bony or cartilaginous and the condition of nasal mucosa. Endoscopic Examination was done to confirm the findings of anterior rhinoscopy, measure the vertical and anteroposterior diameters of the perforation and to exclude the presence of any other intranasal pathology whether inflammatory or neoplastic. The size of perforation was measured endoscopically by using a piece of $\mathrm{x}$ ray film cut to match the size of the perforation. Anteroposterior diameters of the perforations could be measured using a graduated suction tube All patients were subjected to computed tomography of the nose and paranasal sinuses, coronal and axial cuts to define the site and diameters of the perforation and to exclude any other intranasal pathology.

Patients included in the study were divided into two matched groups regarding age, sex and local criteria of the perforation. Group I patients were enrolled in the study during the period from June 2015 to December 2017 and were subjected to open approach with bilateral bipedicled advancement nasoseptal flaps (Figure 1). Group II patients were enrolled in the study during the period from January 2018 to January 2020 and were subjected to endoscopic approach with bilateral bipedicled advancement nasoseptal flaps (Figure 2).

Operative Technique: After taking a written consent, every patient was operated by the two authors of the study under general anesthesia. The nose was packed loosely with xylometazoline-soaked pieces to apply decongestive effect. Approximately $5 \mathrm{~cm} 3$ of $2 \%$ lidocaine with $1: 100,000$ parts epinephrine were injected into the subperichondrial and subperiosteal planes throughout the nasal septum and floor of the nose.

In open approach, a classical external rhinoplasty approach was performed where bilateral alar marginal incisions were started laterally along the caudal edge of the lateral crus; dissection was continued medially down the length of the columella where they were connected via an inverted V-shaped transcolumellar incision. The columellar skin was elevated off the medial crura and skin dissection was continued in a superior direction in the supraperichondrial avascular plane till reaching the nasal bones where the periosteum was elevated using a Joseph-type periosteal elevator. Dissection was performed between the medial crura to gain access to the caudal septal cartilage followed by bilateral caudal septal membrane elevation in a strict sub-mucoperichondrial plane. In endoscopic approach, hemi-transfixion incision (mainly left) was made anterior to the cartilaginous portion of the septum through one side of the membranous septum, and both sides of the mucoperichondrial flaps were then raised around the perforation.

Septal flap dissection was continued in a superior direction till reaching the cartilaginous edge of the perforation where an increased resistance was sometimes met during the dissection due to adherence of the septal flaps to each other with no intervening cartilage. At this stage the dissection was taken downwards to elevate the mucosa off the maxillary crest, nasal floor, and laterally until reaching the root of the inferior turbinate where a back cut was made if needed with a \#15 blade thus developing a bipedicled floor flap. This flap could be mobilized 
medially and in a superior direction on both sides of the nasal septum to close the mucosal perforation on each side. The septal flap elevation was continued dorsally between the superior edge of the perforation and the upper lateral cartilage. In open approach, the upper lateral cartilage was then separated from the septum extramucosally using a \#15 blade.

The roof flap bridging between the superior edge of the perforation and the undersurface of the upper lateral cartilage could be dropped downwards to close the mucosal rent on each side. In cases with large perforations, more length could be added to the roof flap by extending the dissection to include the mucoperichondrium of the undersurface of the upper lateral cartilage. In rare very large perforations, a back cut could be made in the mucosa under the upper lateral cartilage thus transforming the roof flap into a bipedicled flap allowing more downwards advancement.

After completing the roof and floor mucosal flaps around the perforation, they were separated using sharp dissection and the edges were refreshed. The created flaps were advanced and the mucosal perforation on each side was closed, under no tension, using interrupted sutured of coated 50/ vicryl code W9105 (Ethicon Inc, Johnson \& Johnson, New Jersey and Cincinnati, Ohio, US). The used needle was RB-1 plus which is a $12 /$ circle needle with taper point plus, rounded body and $17 \mathrm{~mm}$ length. In open approach, the mucosal flaps were closed on the left side from inside the nasal cavity and on the right side from inside the septal space using interrupted sutures with the needle passing through the lower then upper flap. The used needle holder was Storz needle holder, code 516015 (Karl Storz SE \& Co. KG, Tuttlingen, Germany) with $15 \mathrm{~cm}$ length. In endoscopic approach, the mucosal flaps were closed on the both sides from inside the nasal cavity using interrupted sutures with the needle passing through the lower then upper flap. The left side was much easier provided that both authors are right handed. The used needle holder was Storz extra delicate DRAF Micro Needle Holder, code 799016 (Karl Storz SE \& Co. KG, Tuttlingen, Germany) with $16.5 \mathrm{~cm}$ length.

Finally, in some cases of both groups with week mucosal flaps, traumatized edges of the flap by the dissection process with non-secure sutures, or suturing of the flaps under tension, a connective tissue graft (conchal cartilage) was interposed between the repaired flaps. The conchal cartilage graft was fixed by sutures to the dorsal and caudal septal cartilage to prevent its migration. The graft used should be large enough to extend circumferentially beyond the suture line of the repaired mucosal perforations of both flaps. The repaired flaps were then sutured together along with the interposed graft to obliterate the dead spaces and to reinforce the repair.
In open approach, the upper lateral cartilages were then reattached to the dorsal cartilaginous septum using 50/ vicryl sutures in a horizontal mattress fashion. A columellar strut was usually needed to make up for the loss of tip support following the separation of medial crura from each other as well as from the caudal septum. Despite the perforation, there was usually enough septal cartilage from which to fashion a strut. The strut was inserted in a pocket between the medial crura and fixed in place using 50/ Monoacryl sutures. In endoscopic approach, the hemi-transfixion incision was closed using 50/ vicryl interrupted sutures. In both approaches, nasal stenting and light packing were done to stabilize the repair.

Postoperative Assessment: Removal of the stents was done two weeks postoperative. Patients were assessed one week later for discomfort as felt by the patient and crustations as observed by the physician. Both were graded ad mild, moderate and severe. Endoscopic assessment was performed at weekly intervals after removal of the stents till complete healing of the edges of the perforation occurs for a maximum duration of 3 months. Assessment of the aesthetic outcomes was done 3 months postoperative by assessment of 3 parametrs. The rotation of the nasal tip was assessed by measuring the nasolabial angle between a line from the subnasale to the superior vermilion and a line from the most pointing point of the columella to the subnasale. The aesthetic ideal for the nasolabial angle is defined by a range of $90-100^{\circ}$ in men and $100-110^{\circ}$ in women. Larger angles indicate cephalic rotation of the nasal tip and smaller angles indicate tip dropping. Columellar show below the alar rim was assessed and it should be $24-\mathrm{mm}$. Lower values of columellar show indicate columellar retraction. The width of the mid third of the nose should not be less than $75 \%$ of the width of the alar base extending from one alar crease to the other. Otherwise, this will indicate a pinched mid third of the nose $\mathrm{e}^{[6]}$.

Outcomes of the study included the success of the surgical operation in repair of septal perforation defined as complete or partial closure, comparison between the two surgical approaches regarding operative details including operative time and intraoperative blood loss, and postoperative details regarding patient discomfort, nasal crustations and aesthetic problems. Assessment of the relationship between the success of each approach and the vertical and anteroposterior diameters of the perforation was a secondary outcome for the study.

\section{STATISTICAL ANALYSIS:}

Data were collected, tabulated and statistically analyzed using Statistical Package of Social Science (SPSS) version 23, (IBM corp, Armonk, NY, USA). Descriptive statistics for quantitative data were presented as mean $\left({ }^{-} \mathrm{X}\right)$ and standard deviation (SD). Qualitative data were 
presented as numbers and percentages (\%). Data turned up to be non-normally distributed according to KolmogorovSmirnov test. Chi square test and Fischer Exact teats were used to compare qualitative data of both groups. Mann Whitney $U$ test was used to compare quantitative data of both groups. Two-sided $p$ value of $(<0.05)$ was considered statistically significant, while $p<0.001$ was considered highly significant.

\section{RESULTS}

The present study included forty-three patients with iatrogenic (post septal surgery) septal perforations who were divided into two groups. Group I included 25 patients subjected to open approach with bilateral bipedicled advancement nasoseptal flaps with three cases having conchal cartilage interposition graft (Figure 1). Group II included 18 patients subjected to endoscopic approach with bilateral bipedicled advancement nasoseptal flaps with two cases having conchal cartilage interposition graft (Figure 2). There was no statistically significant difference between the two groups regarding age, sex, anteroposterior and vertical diameters $(p$ value $=0.1,0.82,0.65$ and 0.76 respectively) reflecting matching of the study groups (Table 1).

In the current study, the success rate of open approach in closure of the septal perforation was $80 \%(20 / 25)$ including all three cases with interposition conchal cartilage graft. However, the success rate of the endoscopic approach was $72.2 \%(13 / 18)$ including the two cases with interposition conchal cartilage graft. There was no statistically significant difference between the two groups regarding the success rate $(p=0.55)$ (Table 2). There was a statistically significant relationship between the success of both open and endoscopic approaches and the vertical diameter of the perforation $(p=0.001$ and 0.002 respectively) but not the anteroposterior diameter $(p=0.34$ and 0.17 respectively) (Table 3 ).

The findings of this study showed that the mean operative durations in both groups were 3.16 and 3.13 hours, respectively, with no statistically significant difference $(p=0.73)$. The mean intraoperative blood losses in both groups were 155.6 and 148.33 , respectively, with no statistical significance $(p=0.52)$ (Table 4).

In the current study, there was no statistically significant difference between the two groups regarding crustations ( $p$ value $=0.17)$. However, there was a statistically significant difference between the two groups regarding discomfort and aesthetic problems favoring the endoscopic approach ( $p=0.004$ and 0.04 , respectively) (Table 5). Out of the eight patients $(32 \%)$ having aesthetic problems with the open approach, 4 patients $(16 \%)$ had mildly dropped tip, 2 patients $(8 \%)$ had pinched mid third of the nose and 2 patients $(8 \%)$ had mild columellar retraction. One patient (5.6\%) with the endoscopic approach had mild tip dropping.

Table 1: Demographic and clinical data of study groups

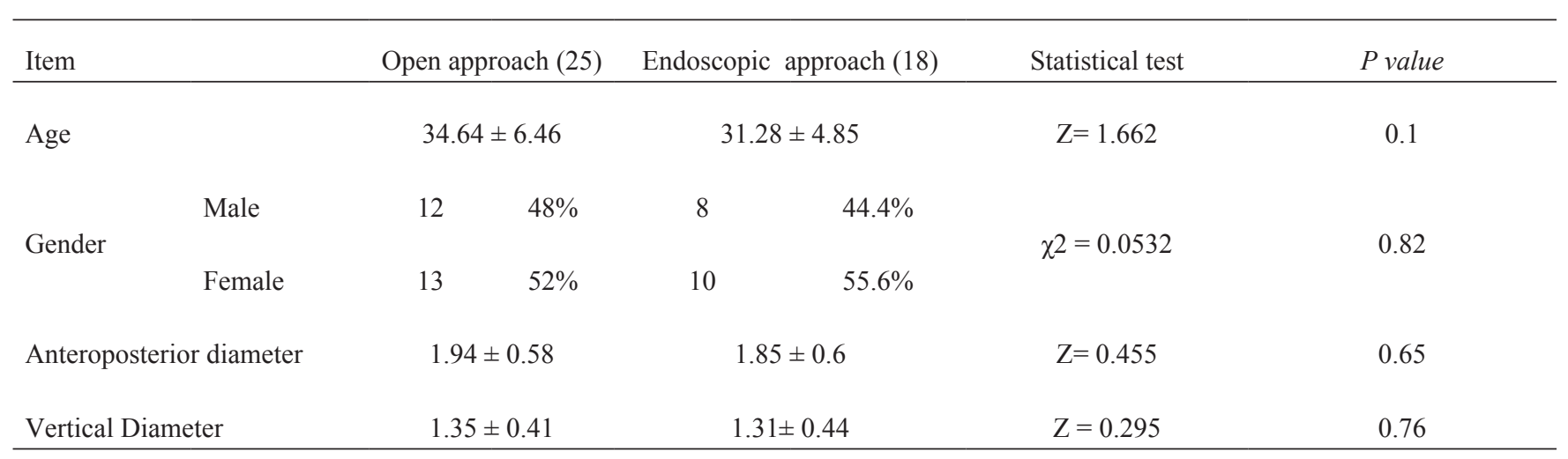

Z: Z value for Mann Whitney U test.

$\chi 2$ : Chi square test value

Table 2: Success of closure of the perforation in study groups

\begin{tabular}{|c|c|c|c|c|c|c|}
\hline \multirow{2}{*}{$\begin{array}{l}\text { Closure } \\
\text { Complete closure }\end{array}$} & \multicolumn{2}{|c|}{ Open approach (25) } & \multicolumn{2}{|c|}{ Endoscopic approach (18) } & \multicolumn{2}{|c|}{$\begin{array}{c}\text { Chi square test } \\
\text { P value }\end{array}$} \\
\hline & 20 & $80 \%$ & 13 & $72.2 \%$ & \multirow[b]{2}{*}{$\chi^{2}=0.3547$} & \multirow[b]{2}{*}{0.55} \\
\hline Incomplete closure & 5 & $20 \%$ & 5 & $27.8 \%$ & & \\
\hline
\end{tabular}

$\chi 2$ : Chi square test value 
Table 3: Correlation between success of the operation and diameters of the perforation

\begin{tabular}{lccc}
\hline Diameter & Complete healing & Incomplete healing & Mann Whitney U Test \\
\hline & & Open approach & \\
& & & \\
Vertical diameter & $1.21 \pm 0.33$ & $1.9 \pm 0.14$ & $\mathrm{Z}=-3.29493$. \\
Anteroposterior diameter & $1.875 \pm 0.58$ & $2.2 \pm 0.57$ & $\mathrm{Z}=0.951$ \\
& & Endoscopic approach & 0.34 \\
Vertical diameter & $1.1 \pm 0.32$ & $1.85 \pm 0.14$ & $\mathrm{Z}=-3.154$ \\
Anteroposterior diameter & $1.73 \pm 0.62$ & $2.15 \pm 0.42$ & $\mathrm{Z}=-1.38002$. \\
\hline
\end{tabular}

$\mathrm{Z}$ : Z value for Mann Whitney U test.

Table 4: Operative details of endoscopic and open approaches

\begin{tabular}{lllll}
\hline Operative detail & Open approach & Endoscopic approach & Mann Whitney U test & $P$ value \\
Operative duration & $3.16 \pm 0.43$ & $3.13 \pm 0.46$ & $\mathrm{Z}=0.345$ & 0.73 \\
Operative bleeding & $155.6 \pm 23.64$ & $148.33 \pm 26.40$ & $\mathrm{Z}=0.64$ & 0.52 \\
\hline
\end{tabular}

$\mathrm{Z}: \mathrm{Z}$ value for Mann Whitney U test.

Table 5: Postoperative complications of open and endoscopic approaches

\begin{tabular}{|c|c|c|c|c|c|}
\hline \multicolumn{2}{|c|}{ Postoperative complication } & \multirow{2}{*}{$\begin{array}{c}\text { Open Approach (25) } \\
10\end{array}$} & \multirow{2}{*}{$\begin{array}{c}\text { Endoscopic Approach (18) } \\
11\end{array}$} & \multirow{3}{*}{$\begin{array}{c}\text { Statistical test } \\
\\
\chi 2=1.867\end{array}$} & \multirow{3}{*}{ 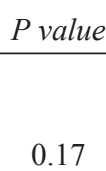 } \\
\hline Crustations & Mild & & & & \\
\hline & & & & & \\
\hline & Moderate & 15 & 7 & & \\
\hline \multirow[t]{3}{*}{ Discomfort } & Mild & 7 & 13 & & \\
\hline & & & & $\chi 2=8.226$ & 0.004 \\
\hline & Moderate & 18 & 5 & & \\
\hline \multirow[t]{3}{*}{ Aesthetic problems } & Present & 8 & 1 & & \\
\hline & & & & $\chi 2=4.422$ & 0.04 \\
\hline & Absent & 17 & 17 & & \\
\hline
\end{tabular}

$\chi 2$ : Chi square test value 


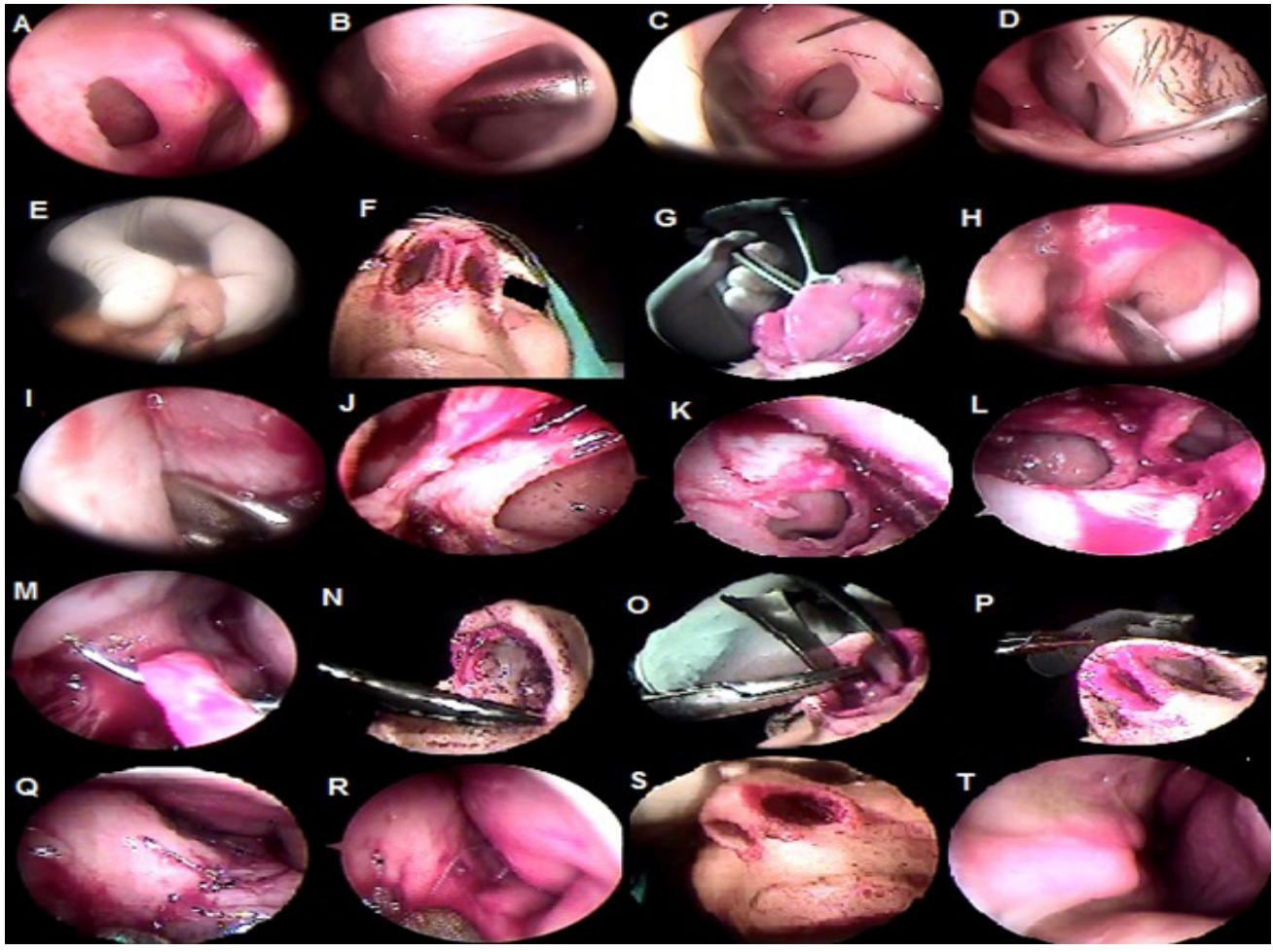

Fig. 1: Open Rhinoplasty Approach with Bipedicled Advancement Flaps Technique: A: Endoscopic view showing septal perforation. B: Measuring the anteroposterior diameter of the perforation using graduated suction tube. C, D: Injection of septal mucosa around the perforation. E: Transcolumellar incision F: Bilateral alar incisions. G: Exposure of the caudal end of the septal cartilage. H: Incision of the posterior edge of the perforation. I, J: Dissection of flaps from remnant of septal cartilage. K: Dissection of superior flap from nasal roof. L: Dissection of inferior flap from nasal floor. M, N: Intranasal stitching of left superior and inferior flaps. O, P: Intraseptal stitching of right superior and inferior flaps. Q: Intranasal view showing stitched left sided mucosal flaps. R: Intraseptal view showing stitched right sided mucosal flaps. S: Closure of the columellar incision. T: Postoperative view showing successful repair of the perforation.

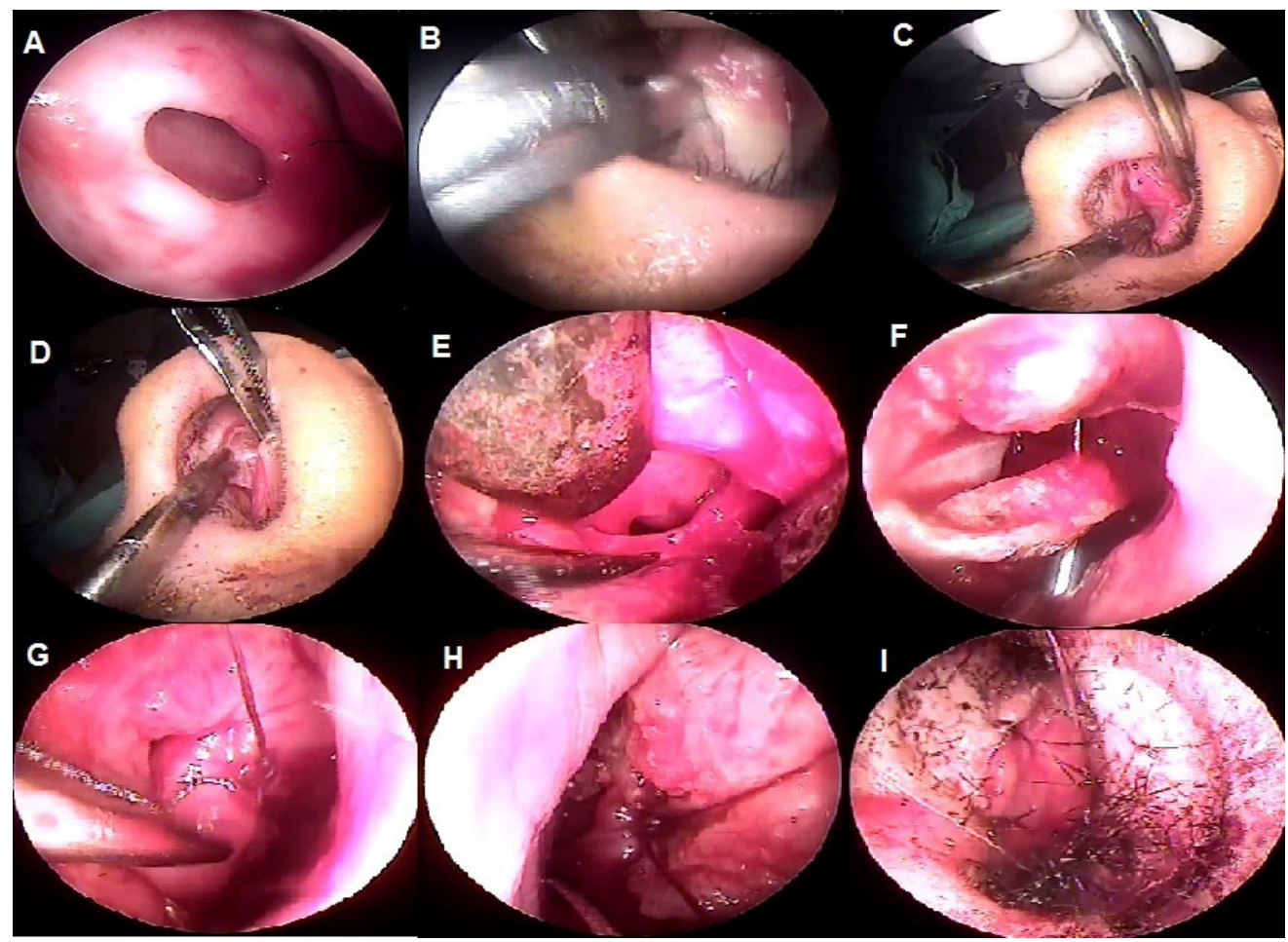

Fig. 2: Endoscopic Approach with Bipedicled Advancement Flaps Technique: A: Endoscopic view showing septal perforation. B: Hemitransfixion incision anterior to the anterior edge of the septal cartilage. C, D: Elevation of the left mucoperichondrial flap. E: Dissection and separation of mucosal flaps around the perforation. F, G: Intranasal stitching of left superior and inferior flaps. H: Intranasal stitching of right superior and inferior flaps. I: Closure of the septal incision. 


\section{DISCUSSION}

Surgical repair of septal perforation can be carried out using either the (closed intranasal technique or open technique). The intranasal technique has the advantage of better cosmetic results without external scarring, but it has the disadvantage of limited operating field. The open technique is preferred by many surgeons due to its wide operating field and binocular vision. This wide operating field facilitates dealing with large and posterior perforations with easier access to superior and posterior margins of any septal perforation ${ }^{[4]}$.

In the current study, no significant statistical difference was found between the two study groups regarding age, sex, vertical and horizontal diameters ( $p>0.05$ for all). This reflects the matching of both groups, so any statistical difference between the two groups was not attributed to any initial baseline difference between them.

In the present study, open rhinoplasty approach with bipedicled advancement nasoseptal flaps achieved a success rate of $80 \%(20 / 25)$ compared with endoscopic approach which achieved a success rate of $72.2 \%(13 / 18)$ however this difference did not reach statistical significance $(p=0.55)$. By reviewing the literature, several studies evaluated the use of open rhinoplasty approach with mucosal flap advancement technique. It was first described in 1978 by Strelzow and Goodman ${ }^{[7]}$ for repair of nasal septal perforation and in 1982 they used this approach for extensive vertical axis perforations utilizing two superior and inferior-hinge bipedicled flaps, with an anterior and a posterior freeing incision. On the other hand, when confronted with extensive horizontal axis perforations, two anterior and posterior-hinge bipedicled flaps were utilized, together with a superior and an inferior freeing incision ${ }^{[8]}$. Several further studies evaluated the open rhinoplasty approach with bilateral bipedicled advancement flaps with variable success rates $^{[9-12]}$ (Table 6) which are noted to be higher than the success rate in our study. This can be attributed to the different sample sizes between our study and these studies and variations of perforation characteristics.

Several cases illustrate the superiority of the open over endoscopic approach regarding the surgical exposure and feasibility of surgical maneuvers for difficult cases of septal perforation. These cases include any case of septal perforation with resection of the caudal septal cartilage causing fibrosis in this area which makes caudal access to the septum difficult with obliterated dissection planes. In this case, the open approach offers a dorsal access to the septum with better dissection planes especially posterior to the perforation ${ }^{[10]}$. Another case is any case with large septal perforation especially with large vertical diameter which needs dissection and advancement of the mucosa lining the undersurface of the upper lateral cartilage. Such step is accessible with the open approach rather than the intranasal approach ${ }^{[10]}$.Finally, the open approach allows suturing of the mucosal flap from both sides of the flap, namely from the nasal cavity and from inside the septal space giving a better chance for complete closure of the perforation ${ }^{[10]}$.

On the other hand, the main drawbacks of the open approach are mainly cosmetic including tip drop, pinched mid third of the nose and cephalic rotation of the nasal tip. Drop of the nasal tip could be caused by failure of the supporting mechanism of the nasal tip due inadequate suturing of the medial crura of the lower lateral cartilage at the end of the operation. Sometimes a columellar strut between the medial crura is needed to further support the nasal tip. The pinched mid third of the nose is due to pulling of the upper lateral cartilage inferiorly during mobilization and advancement of the superior septal mucosal flap which is attached to the upper lateral cartilage. The cephalic rotation of the nasal tip is caused by the tension imposed on the caudal septal mucosa and the medial crura by advancement of the bipedicled flaps to close the mucosal defect ${ }^{[1]}$.

In open approach group of the current study, out of the eight patients (32\%) having cosmetic problems; 4 (16\%) patients had mild dropped tip, 2 patients $(8 \%)$ had pinched mid third of the nose and 2 patients $(8 \%)$ had mild columellar retraction. Four of these patients necessitated further corrective surgery to improve the cosmetic outcome. Our findings are less than the findings of Foda et al. ${ }^{[10]}$ who reported one case $(5 \%)$ with dorsal irregularities after open approach for nasal septal perforation repair. Ozdek et al ${ }^{[13]}$ reported that there was mild columellar retraction in five out of 29 patients $(18 \%)$ with no additional surgery required to repair columellar retraction in these patients.

The endoscopic approach for repair of nasal septal perforation repair was described by, Meyer in $1964^{[14]}$ who proposed, for caudal perforations, to use sliding flaps from the nasal fossae floor. Several further studies evaluated the endoscopic approach with bilateral bipedicled advancement nasoseptal flaps with variable success rates $^{[15-19]}$ (Table 6) which are noted to be higher than the success rate in our study. This can be attributed to the different sample sizes and some modifications in the surgical technique in some studies including the use of different interposition graft materials. The advantages of endoscopic approach are its better cosmetic outcome with no external scars, optimal visualization of the difficult to access areas of 
the nose with good control of perforation margins. The drawbacks are that it may be time-consuming and can be quite difficult to perform, requiring some years of training to get the required endoscopic experience ${ }^{[20]}$.

In the current study, the mean operative durations in both groups were 3.16 and 3.13 hours, respectively, with no statistically significant difference $(p=0.73)$. The mean intraoperative blood losses in both groups were 155.6 and 148.33, respectively, with no statistical significance $(p=0.52)$. The long operative duration is explained by the extensive dissection needed in bipedicled advancement nasoseptal flaps technique to raise the mucosal flaps superiorly and inferiorly reaching the lateral wall of the nose along with the release incisions. This consumed long operative time and extensive dissection is associated with increased bleeding. However, the amount of blood loss with open approach which was $155.6 \pm 23.64 \mathrm{~mL}$ is an average for blood loss measured in previous studies assessing open rhinoplasty approach. Tabrizi et al. ${ }^{[21]}$ stated that the average blood loss during open rhinoplasty approach was $132.12 \pm 78.53 \mathrm{ml}$. However, Eftekharian and Rajabzadeh $^{[22]}$ stated that the average blood loss was $199.6 \pm 73.05 \mathrm{~mL}$.
Many previous studies stated that the size of the perforation is one of the most important predictive factors for successful repair for nasal septal perforation ${ }^{[23]}$. In the current study, there was a statistically significant relationship between the success of both open and endoscopic approaches and the vertical diameter of the perforation $(p=0.001$ and 0.002 , respectively) but not the anteroposterior diameter $(p=0.34$ and 0.17 , respectively $)$. Kridel $^{[24]}$ stated that vertical diameter is the most important perforation dimension. This logical relationship between the bipedicled advancement technique and the vertical diameter is because flap advancement is made in a vertical direction with need for less distance for such advancement to achieve better perforation closure without tension at the suture lines. This principle is applicable to any technique involving the use of an advancement flap from the nasal floor or nasal roof whether endoscopic or open.

Finally, the limitations of our study included the relatively small number of the study groups. This can be explained by the fact that most septal perforations are asymptomatic. As a rule, the approach for management of nasal septal perforation should be individualized and tailored according to the status of each perforation.

Table 6: Previous studies evaluating open and endoscopic approaches with bilateral bipedicled advancement nasoseptal flaps

\begin{tabular}{|c|c|c|c|c|}
\hline Author & Year & $\begin{array}{l}\text { Number } \\
\text { of } \\
\text { patients }\end{array}$ & Flap design & Success rate \\
\hline \multicolumn{5}{|c|}{ Open approach } \\
\hline Kridel et al. ${ }^{[9]}$ & 1998 & 12 & $\begin{array}{l}\text { Open approach with an acellular human dermal allograft as a graft material } \\
\text { between the nasal mucosa bipedicled sliding flaps, in patients presenting with } \\
\text { septal perforations with diameters }<3 \mathrm{~cm} \text {. }\end{array}$ & $92 \%$ \\
\hline Foda $^{[10]}$ & 1999 & 20 & $\begin{array}{l}\text { External rhinoplasty approach in patients in which septal perforations and } \\
\text { external nasal deformities coexisted with interposition of a connective tissue graft } \\
\text { (temporalis fascia autograft or dermal allograft) between the advanced mucosal } \\
\text { flaps. }\end{array}$ & $90 \%$ \\
\hline Bryan et al..$^{[11]}$ & 2003 & 10 & $\begin{array}{l}\text { Open technique and bipedicled sliding flaps using porcine small intestinal } \\
\text { submucosa as interposition graft, on septal perforations ranging between } 0.4 \mathrm{~cm} \\
\text { and } 2 \mathrm{~cm} \text {. }\end{array}$ & $100 \%$ \\
\hline $\begin{array}{l}\text { Wong and } \\
\text { Raghavan }^{[12]}\end{array}$ & 2010 & 28 & $\begin{array}{l}\text { Open rhinoplasty approach with bilateral superior and inferior nasal mucosal } \\
\text { advancement flaps and acellular porcine collagen placed in between. }\end{array}$ & $96 \%$ \\
\hline \multicolumn{5}{|c|}{ Endoscopic Approach } \\
\hline Fairbanks $s^{[15]}$ & 1980 & 20 & $\begin{array}{l}\text { Bilateral bipediccled advancement flaps with interposition of a graft metarial } \\
\text { consisting of temporal fascia or cranial periosteum (pericranium) }\end{array}$ & $95 \%$ \\
\hline Lee $\mathrm{KC}$ et al. ${ }^{[16]}$ & 2008 & 11 & $\begin{array}{l}\text { Bilateral mucoperichondrial flaps with interposition } \\
\text { graft incorporating Surederm }{ }^{\mathrm{TM}} \text {. }\end{array}$ & $90.9 \%$ \\
\hline $\begin{array}{l}\text { Giacomini } \\
\text { et al. }^{[17]}\end{array}$ & 2011 & 14 & $\begin{array}{l}\text { 3-layer reconstruction of the septum through a horizontal advancement of the } \\
\text { bipedicled mucoperichondrial flap with autogenous auricular conchal grafts. }\end{array}$ & $85.7 \%$ \\
\hline $\begin{array}{l}\text { Rokkjærw } \\
\text { et al. }{ }^{[18]}\end{array}$ & 2010 & 19 & $\begin{array}{l}\text { An endonasal approach with dissection of bilateral bipedicled mucoperichondrial/- } \\
\text { periosteal advancement flaps and interposition of a septal or conchal cartilage } \\
\text { graft. }\end{array}$ & $84 \%$ \\
\hline Ma et al..$^{[19]}$ & 2011 & 12 & $\begin{array}{l}\text { Pedicled mucoperichondrial flap from the septal mucosa and } \\
\text { nasal floor with interposition of acellular dermal matrix. }\end{array}$ & $91.7 \%$ \\
\hline
\end{tabular}




\section{CONCLUSION}

Both open and endoscopic approaches with bilateral bipedicled advancement nasoseptal mucosal flaps are successful options for repair of nasal septal perforation with comparable results and operative details. However, the open approach may cause more discomfort and aesthetic problems than the endoscopic approach with a significant difference. The vertical diameter of the perforation is a significant determinant of the success of the approaches utilizing bilateral bipedicled advancement nasoseptal mucosal flaps.patients with ANSD in order to improve their ability.

\section{CONFLICT OF INTEREST}

There are no conflicts of interests.

\section{REFERENCES}

1. Kridel RW. Septal perforation repair. Otolaryngologic Clin N Am 1999; 32:695-724

2. Romo T, Toffel PH. Nasal septal perforation. In: Gates GA, editor. Current therapy in Otolaryngology Head and Neck Surgery. St. Louis: Mosby; 1998. p. 339-44.

3. Romo $\mathrm{T} 3^{\text {rd }}$, Sclafani AP, Falk AN, Toffel PH. A graduated approach to the repair of nasal septal perforations. Plast Reconstr Surg. 1999; 103:66-75

4. Re M, Paolucci L, Romeo R, Mallardi V. Surgical treatment of nasal septal perforations. Our experience. Acta Otorhinolaryngologica Italica. 2006; 26(2):102-109.

5. Yildirim G, Onar V, Sayin I, Onol SD, Aydin T. The reconstruction of nasal septal perforation with high density porous polyethylene covered with fascia lata: an experimental study on rabbit model. Clin Exp Otorhinolaryngol. 2011; 4: 137-41.

6. Zimbler MS. Aesthetic Facial Analysis. In: Flint PW, Haughey BH, Lund VJ, et al, eds. Cummings Otolaryngology Head \& Neck Surgery. Fifth edition. Philadelphia, Mosby Inc, 2010, 269-280.

7. Strelzow VV, Goodman WS. Nasoseptal perforations closure by external rhinoplasty. J Otolaryngol. 1978; 7:43-8.

8. Goodman WS, Strelzow VV. The surgical closure of nasoseptal perforations. Laryngoscope. $1982 ; 92: 121-4$
9. Kridel RW, Foda H, Lunde KC. Septal perforation repair with acellular human dermal allograft. Arch Otolaryngol Head Neck Surg. 1998; 124(1):73-8.

10. Foda HM. The one-stage rhinoplasty septal perforation repair. J Laryngol Otol. 1999; 113:728-33.

11. Bryan TA, Zimmerman J, Rosenthal M, Pribitkin EA. Nasal septal repair with porcine small intestinal submucosa. Arch Facial Plast Surg. 2003; 5:528-9.

12. Wong S, Raghavan U. Outcome of surgical closure of nasal septal perforation. J Laryngol Otol. 2010; $124: 868-874$

13. Ozdek A, Bayır O, Dündar Y, Tatar EC, Saylam G, Korkmaz MH. Closure of nasal septal perforations using bilateral intranasal advancement/rotation flaps. Kulak Burun Bogaz Ihtis Derg. 2014 May-Jun; 24(3):123-8.

14. Meyer R. Repair techniques in perforations of the nasal septum. Ann Plast Surg Esthet. 1992;37: 154-61.

15. Fairbanks DNF. Closure of nasalseptal perforations Arch Otolaryngol Head Neck Surg 1980;106:509-13.

16. Lee KC, Lee NH, Ban JH, Jin SM. Surgical treatment using an allograft dermal matrix for nasal septal perforation. Yonsei Med J. 2008; 49:244-248.

17. Giacomini PG, Ferraro S, Di Girolamo S, Ottaviani F. Large nasal septal perforation repair by closed endoscopically assisted approach. Ann Plast Surg. 2011; 66:633-636.

18. Rokkjær MS, Barrett TQ, Petersen CG. Good results after endonasal cartilage closure of nasal septal perforations. Dan Med Bull. 2010 Oct;57(10):A4196.

19. Ma YX, Tao AZ, Lu C, Tian H, Dong BC. Endoscopic repair of nasal septal perforation with acellular dermal matrix and pedicled mucoperichondrial flap. Zhonghua Er Bi Yan Hou Tou Jing Wai Ke Za Zhi. 2011 Jun; 46(6):455-8.

20. Alobid I. Endoscopic approach for management of septal perforation. Eur Arch Otorhinolaryngol. 2019 Aug;276(8):2115-2123.

21. Tabrizi R, Eftekharian H, Pourdanesh F, Khaghaninejad MS. Does oral clonidine premedication decrease bleeding during open rhinoplasty? J Craniofac Surg. 2014 May; 25(3):1101-3 
22. Eftekharian HR, Rajabzadeh Z. The Efficacy of Preoperative Oral Tranexamic Acid on Intraoperative Bleeding During Rhinoplasty. J Craniofac Surg. 2016 Jan; 27(1):97-100.

23. Kim SW, Rhee CS. Nasal septal perforation repair: predictive factors and systematic review of the literature. Curr Opin Otolaryngol Head Neck Surg. 2012; 20:58-65.

24. Kridel RW. Considerations in the etiology, treatment, and repair of septal perforations. Facial Plast Surg Clin North Am. 2004; 12:435-450. 